\title{
DDX46 silencing inhibits cell proliferation by activating apoptosis and autophagy in cutaneous squamous cell carcinoma
}

\author{
QUAN LIN $^{1 *}$, HONG-JUAN JIN ${ }^{1 *}$, DUO ZHANG ${ }^{1}$ and LING GAO ${ }^{2}$ \\ Departments of ${ }^{1}$ Plastic Surgery and ${ }^{2}$ Radiation Oncology, The First Hospital of Jilin University, \\ Changchun, Jilin 130021, P.R. China
}

Received July 23, 2019; Accepted March 13, 2020

DOI: $10.3892 / \mathrm{mmr} .2020 .11509$

\begin{abstract}
DEAD-Box Helicase 46 (DDX46) is an ATP-dependent RNA helicase that plays a central role in transcription splicing and ribosome assembly. However, the role of DDX46 in cutaneous squamous cell carcinoma (CSCC) remains to be elucidated. The aim of the present study was to investigate the role of DDX46 in CSCC by assessing DDX46 expression levels in CSCC tissues and cell lines. The effect of DDX46 silencing on CSCC cell proliferation, apoptosis and autophagy were also analyzed. It was demonstrated that DDX46 was significantly overexpressed in CSCC tissues and cells $(\mathrm{P}<0.05)$. Furthermore, it was found that DDX46 silencing could dramatically inhibit cell proliferation $(\mathrm{P}<0.05)$. Moreover, cell apoptosis and autophagy were activated in DDX46 silencing groups $(\mathrm{P}<0.05)$. Therefore, the present results suggested that DDX46 was overexpressed in CSCC and that DDX46 silencing can inhibit cell proliferation by inducing apoptosis and activating autophagy. Thus, DDX46 may serve as a novel potential therapeutic target for CSCC.
\end{abstract}

\section{Introduction}

Cutaneous squamous cell carcinoma (CSCC) is one of the most common cancer types, accounting for 25-35\% of cutaneous malignancies (1). CSCC develops from epidermal keratinocytes or adnexal squamous epithelial cells (2). Currently, immunosuppression factors that are sensitive to sunlight or UV radiation and genetic factors are thought to be closely associated with CSCC (3). Treatments for cutaneous squamous cell carcinoma include excision, radiotherapy, photodynamic therapy and topical drug treatment (4).

Correspondence to: Dr Ling Gao, Department of Radiation Oncology, The First Hospital of Jilin University, 71 Xinmin Street, Changchun, Jilin 130021, P.R. China

E-mail: lingaomail@163.com

*Contributed equally

Key words: cutaneous squamous cell carcinoma, DEAD-Box Helicase 46, proliferation, apoptosis, autophagy
DEAD-box (DDX) RNA helicases are a large ATP-dependent RNA helicases family, which originates from a wide number of organisms ranging from prokaryotes, including viruses, to eukaryotes such as yeast, plants and animals (5). DDX is involved in almost every cellular process of RNA metabolism, from RNA synthesis to RNA degradation and plays important roles during cell development and growth in almost all organisms (6). DDX46 is a member of the DDX RNA helicase family located on chromosome 5q31.1 and plays a critical role in transcript splicing and ribosome assembly (7). Previous studies $(7,8)$ have shown that DDX46 is abnormally expressed and plays an oncogenic role in various tumors, and is also involved in tumorigenesis and cancer progression. However, the role of DDX46 in CSCC is still not fully understood.

Therefore, in the present study, three pairs of CSCC tissues and corresponding adjacent tissues were collected, and the expression level of DDX46 was assessed. Furthermore, the effect of DDX46 silencing on CSCC cell proliferation, apoptosis and autophagy was analyzed. To our best knowledge, the present study is the first to identify the possible role of DDX46 in CSCC.

\section{Materials and methods}

Clinical specimens and cell lines. Human CSCC A431 and SCL-1 cells, and human keratinocyte $\mathrm{HaCaT}$ cells were purchased from Shanghai Enzyme Biological Technology Co., Ltd. In addition, three pairs of CSCC tissues and corresponding adjacent tissues were collected from the Department of Plastic Surgery, The First Hospital of Jilin University from September 2015 to November 2018. All the specimens were confirmed for CSCC by clinical and pathological diagnosis. Consent was obtained from the patients and their families. The present study was informed and approved by the Ethics Committee of The First Hospital of Jilin University.

Reagents and instruments. DMEM and FBS were purchased from Santa Co., Ltd. DMSO, crystal violet and tryptase were purchased from Sigma-Aldrich (Merck KGaA). Cell Counting Kit-8 (CCK-8) kits, Annexin V/PI cell apoptosis detection kits and TaqMan $^{\mathrm{TM}}$ reverse transcription reagents (cat. no. 4304134) were obtained from Santa Cruz Biotechnology, Inc. TRIzol ${ }^{\circledR}$ kit, the transfection reagent Lipofectamine $3000^{\circledR}$ and 
3,3'-diaminobenzidine (DAB) reagent kit were provided by Thermo Fisher Scientific, Inc. Rabbit anti-DDX46 (1:500; cat. no. ab72083) antibody was purchased from Abcam. The forward $(\mathrm{F})$ and reverse $(\mathrm{R})$ primers sequences for RT-qPCR of DDX46 were designed and synthesized by Arraystar, Inc., and were as follows: DDX46 F, 5'-AAAATGGCGAGAAGAG CAACG-3' and R, 5'-CATCATCGTCCTCTAAACTCCAC-3'; GAPDH F, 5'-TGACTTCAACAGCGACACCCA-3' and R, CACCCTGTTGCTGTAGCCAAA-3'. The preparation and packaging of DDX46 gene RNAi target sequence and shDX46 lentivirus (shDDX46) were designed and synthesized by Arraystar, Inc.

$R T$ - $q P C R$. Total RNAs of CSCC tissues and cells were extracted with TRIzol ${ }^{\circledR}$ reagent (Invitrogen; Thermo Fisher Scientific, Inc.). Total RNA was reverse transcribed into cDNA at room temperature using $\operatorname{TaqMan}^{\mathrm{TM}}$ reverse transcription reagents (cat. no. 4304134; Thermo Fisher Scientific, Inc.). qPCR was subsequently performed using the iScript ${ }^{\mathrm{TM}} \mathrm{cDNA}$ Synthesis kit (cat. no. 1708890; Bio-Rad Laboratories, Inc.). The PCR conditions were as follows: $95^{\circ} \mathrm{C}$ for $3 \mathrm{~min}$, followed by 40 cycles of $95^{\circ} \mathrm{C}$ for $10 \mathrm{sec}, 60^{\circ} \mathrm{C}$ for $30 \mathrm{sec}$ and $72^{\circ} \mathrm{C}$ for $30 \mathrm{sec}$, according to the manufacturer's protocol of the PCR kit. The relative levels were assessed by $2^{-\Delta \Delta \mathrm{Cq}}$ method (9); $\Delta \mathrm{Cq}=\mathrm{Cq}_{\text {target }}-\mathrm{Cq}_{\mathrm{GAPDH}}$.

Western blotting. Total protein of CSCC tissues and cells were collected with RIPA buffer (Sigma-Aldrich; Merck KGaA). Protein concentrations were determined with a BCA assay (Bio-Rad Laboratories, Inc.). Then, a total of $20 \mu \mathrm{g}$ protein per lane was transferred to the nitrocellulose membrane after $10 \%$ SDS-PAGE and blocked by 5\% TBST (0.1\% Tween-20) for $1 \mathrm{~h}$ at room temperature. The membranes were incubated with rabbit anti-DDX46 (1:1,000; cat. no. ab72083; Abcam), rabbit anti-Bcl-2 antibody (1:1500; cat. no. ab59348; Abcam), rabbit anti-Survivin antibody (1:1,000; cat. no. ab469; Abcam), rabbit anti-Bax antibody (1:1,000; cat. no. ab53154; Abcam), rabbit anti-Cleaved Caspase-3 antibody (1:1,000; cat. no. ab2302; Abcam), rabbit anti-Beclin 1 antibody (ab62557) (1:1,000; cat. no. ab62557; Abcam), rabbit anti-microtubule-associated protein 1A/1B-light chain 3 (LC3) antibody $(1: 1,000$; cat. no. ab128025; Abcam) and anti- $\beta$-actin $(1: 2,000$; cat. no. ab8227; Abcam) at $4^{\circ} \mathrm{C}$ overnight. The PVDF membrane was washed three times with TBST and incubated at room temperature for $2 \mathrm{~h}$ with horseradish peroxidase-conjugated secondary antibody (1:2,000; cat. no. ab97051; Abcam). Blot bands were visualized by ECL systems (Pierce; Thermo Fisher Scientific, Inc.). Densitometry was performed by using ImageJ v1.47 software (National Institutes of Health) (10).

Cell transfection. The preparation and packaging of DDX46 gene RNAi target sequence (shDDX46) and negative control sequence (shNC) were designed and synthesized by Arraystar, Inc. short hairpin (sh)RNA sequence of DDX46 was 5'-AGAAATCACCAGGCTCATA-3', and the negative control shRNA(shNC)sequencewas5'-TTCTCCGAACGTGTCACGT-3'. The quantity of siRNA transfected was $50 \mathrm{nM}$. Cells (1x10 $5 /$ well) were transfected using Lipofectamine 3000 reagent (Invitrogen; Thermo Fisher Scientific, Inc.). Then, $48 \mathrm{~h}$ after transfection, the transfection efficiency was evaluated by labeling vectors with green fluorescence protein (GFP) to ensure that cells were successfully transfected, and evaluated by RT-qPCR using the same steps as mentioned above).

CCK-8 assay. Transfected cells in the logarithmic growth stage were collected and inoculated into 96 -well plates with density of $2 \times 10^{3}$ cells per pore. Each group was assessed with three multiple pores. After adherence, the cells were replaced with 100 ml RPMI-1640 medium (Gibco; Thermo Fisher Scientific, Inc.).containing $10 \mathrm{ml} \mathrm{CCK}-8$ reagent and incubated for $2 \mathrm{~h}$ at $37^{\circ} \mathrm{C}$ according to the manufacturer's instructions. The absorbance $(D)$ of each pore were measured at $450 \mathrm{~nm}$ by enzyme label. The $D$ values of the cells in each group were measured at 24, 48, 72 and $96 \mathrm{~h}$. The growth curves of each group cells were drawn according to the measured $D$ value.

Colony formation assay. Transfected cells in the logarithmic growth stage were digested with $0.5 \%$ trypsin (Gibco; Thermo Fisher Scientific, Inc.) at room temperature for $5 \mathrm{sec}$ and seeded in 6-well plates with $1 \times 10^{5} /$ well. After cultured for 2 weeks, 6 -well plates were washed twice with PBS and cells were fixed with $2 \%$ paraformaldehyde (PFA) at $37^{\circ} \mathrm{C}$ for $30 \mathrm{~min}$. Then, cells were stained with $0.5 \%$ crystal violet for $15 \mathrm{~min}$ at $37^{\circ} \mathrm{C}$. Cell colony forming units were imaged under a confocal microscope (Nikon Corporation; magnification, $\mathrm{x} 400$ ) and analyzed using ImageJ v1.47 software (National Institutes of Health) (10).

5-Ethynyl-2'-deoxyuridine (EdU) assay. Transfected cells in the logarithmic growth stage were digested with $0.5 \%$ trypsin (Gibco; Thermo Fisher Scientific, Inc.) at room temperature for $5 \mathrm{sec}$ and seeded in 24-well plates with $1 \times 10^{4} /$ well. After cultured for $24 \mathrm{~h}, 5 \mu \mathrm{l}$ EdU reagent (Sigma-Aldrich; Merck KGaA)was added to each dish and incubated for $2 \mathrm{~h}$ at $37^{\circ} \mathrm{C}$. Then, plates were washed twice with PBS and cell were fixed with $2 \% \mathrm{PFA}$ for $30 \mathrm{~min}$ at $37^{\circ} \mathrm{C}$. EdU positive cells were visualized and photographed under fluorescence microscope (BD Biosciences; magnification, $\mathrm{x} 400$ ), and analyzed using ImageJ v1.47 software (National Institute of Health).

Flow cytometry. Transfected cells in the logarithmic growth stage were digested with $0.5 \%$ trypsin (Gibco; Thermo Fisher Scientific, Inc.) at room temperature for $5 \mathrm{sec}$ and seeded in 6 -well plates with $1 \times 10^{4} /$ well. After cultured for $24 \mathrm{~h}$, the cells were collected and washed twice with pre-cooled PBS. Then, cells were re-suspended with $1 \mathrm{X}$ combined buffer (Sigma-Aldrich; Merck KGaA) and the cell density was adjusted to $\sim 1 \times 10^{6} / \mathrm{ml}$. Then, $100 \mathrm{ml}$ cell fluid was added to the flow tube, $5 \mu \mathrm{l}$ Annexin V-FITC and $5 \mu \mathrm{l}$ PI solution were added into flow tube to stain cells for $20 \mathrm{~min}$ in the dark at $4^{\circ} \mathrm{C}$. Then, $400 \mathrm{ml}$ combined buffer was added and the apoptotic rate was detected by a FACSCalibur flow cytometer (Becton-Dickinson and Company) for cell-cycle distribution analysis using Cell Quest Software (v5.1; Becton-Dickinson and Company).

Statistical analysis. SPSS v17.0 (SPSS, Inc.) software were used for statistical analyses. Data are presented as the mean \pm SD of three experimental repeats. Student's t-test and $\chi^{2}$ test were performed among two groups, one-way ANOVA followed by 

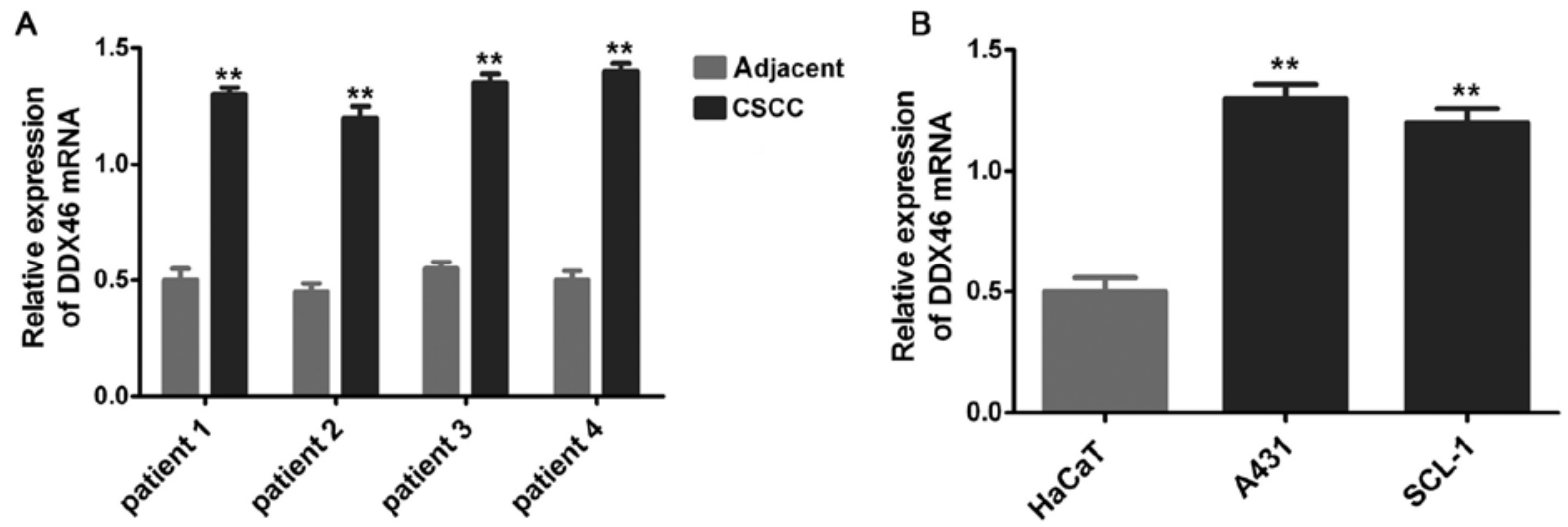

Figure 1. DDX46 mRNA is significantly overexpressed in CSCC tissues and cell lines. (A) DDX46 mRNA expression level in CSCC tissues. $\mathrm{n}=4$, ${ }^{* *} \mathrm{P}<0.01$ vs. adjacent tissues. (B) DDX46 mRNA expression level in A431 and SCL-1 cells. ${ }^{* *} \mathrm{P}<0.01$ vs. HaCaT cells. CSCC, cutaneous squamous cell carcinoma; DDX46, DEAD-Box Helicase 46.
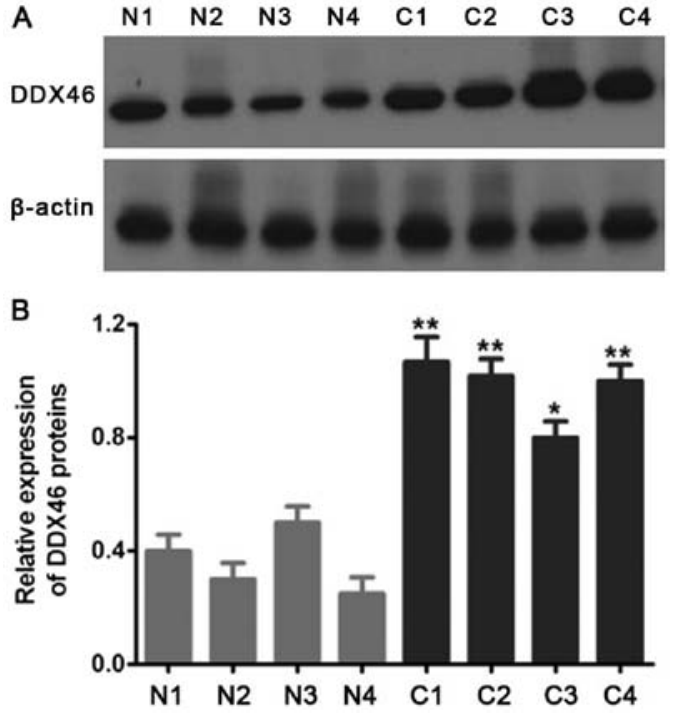

Figure 2. DDX46 protein is overexpressed in CSCC tissues. (A) Western blotting results. (B) Relative protein expression level of DDX46. $\mathrm{n}=4$. ${ }^{*} \mathrm{P}<0.05$ and ${ }^{* *} \mathrm{P}<0.01$ vs. adjacent tissues. CSCC, cutaneous squamous cell carcinoma; DDX46, DEAD-Box Helicase 46; N, adjacent non-cancerous tissue; C, cancer tissue.

Tukey's multiple comparison tests were performed among three groups. $\mathrm{P}<0.05$ was considered to indicate a statistically significant difference.

\section{Results}

DDX46 is overexpressed in CSCC tissues. In the present study, the expression level of DDX46 in three pairs of CSCC tissues and corresponding adjacent tissues was assessed using RT-qPCR and Western blot assay. The RT-qPCR and Western blot results demonstrated that DDX46 mRNA $(\mathrm{P}<0.01$; Fig. 1) and protein $(\mathrm{P}<0.05$; Figs. 2 and 3$)$ expression levels were significantly overexpressed in CSCC cells, and also in CSCC tissues $(n=4)$ compared with corresponding adjacent tissues.

shRNA is successfully transfected into CSCC cells. shDDX46 and shNC were transfected into A431 and SCL-1 cells. Then, $48 \mathrm{~h}$ after transfection using a fluorescence microscope GFP
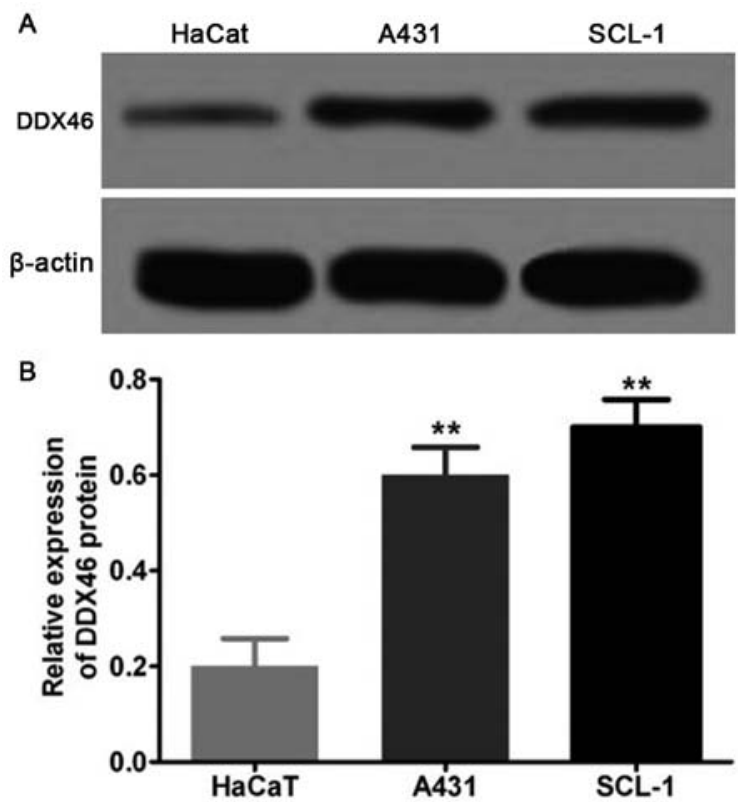

Figure 3. DDX46 proteins are overexpressed in CSCC cells. (A) Western blotting results. (B) Relative protein expression level of DDX46. ${ }^{* *} \mathrm{P}<0.01 \mathrm{vs.} \mathrm{HaCaT}$ cells. CSCC, cutaneous squamous cell carcinoma; DDX46, DEAD-Box Helicase 46.

was observed in A431 and SCL-1 cells (Fig. 4A). RT-qPCR results indicated that DDX46 mRNA expression levels were significantly decreased in the shDDX46 group compared with the shNC group ( $\mathrm{P}<0.05$; Fig. 4B).

DDX46 silencing inhibits cell proliferation. CCK-8, colony formation and EdU assay were used to analyze the effect of DDX46 on cell proliferation. CCK-8 assay results demonstrated that the proliferative ability of cells was significantly decreased in the shDDX46 group compared with the control group $(\mathrm{P}<0.05$; Fig. 5). Furthermore, colony formation assay results suggested that the number of colony-forming units were significantly reduced in the shDDX46 group $(\mathrm{P}<0.05$; Fig. 6) compared with the shNC group. In addition, it was found that the number of EdU positive cells was significantly decreased in the shDDX46 group compared with the shNC group $(\mathrm{P}<0.05$; Fig. 7$)$. 

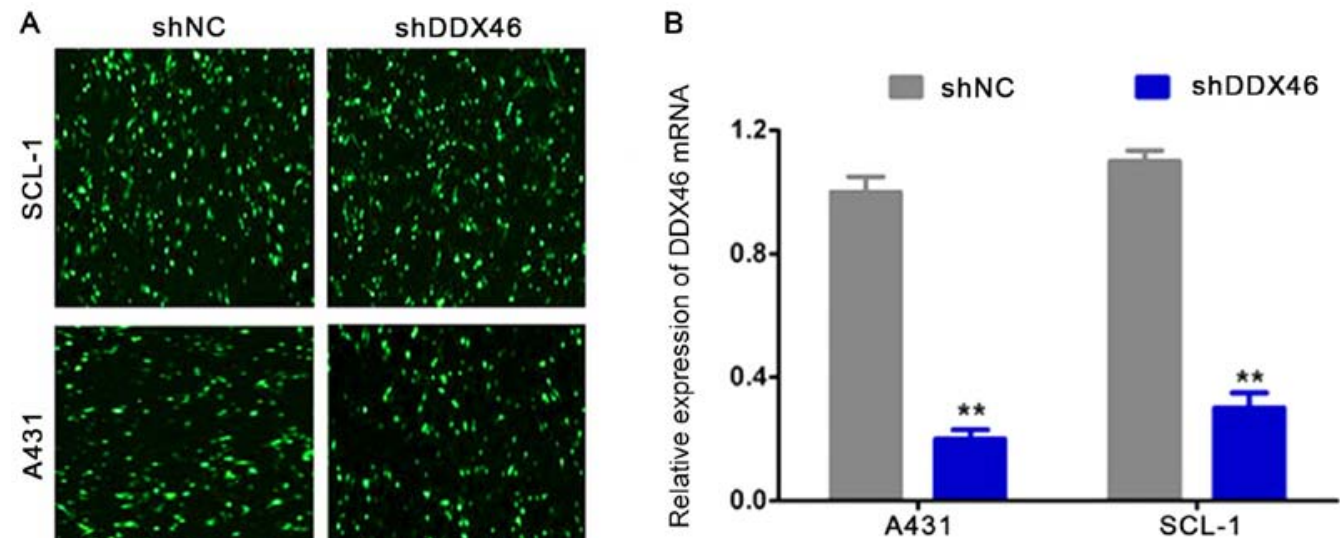

Figure 4. shRNA is successfully transfected into A431 and SCL-1 cells. (A) Green fluorescence was observed in A431 and SCL-1 cells under a fluorescence microscope. (B) Reverse transcription-quantitative PCR results indicated that DDX46 mRNA expression levels were significantly decreased in the shDDX46 group. ${ }^{* *} \mathrm{P}<0.01$ vs. shNC. shRNA, short hairpin RNA; DDX46, DEAD-Box Helicase 46; NC, negative control.

A

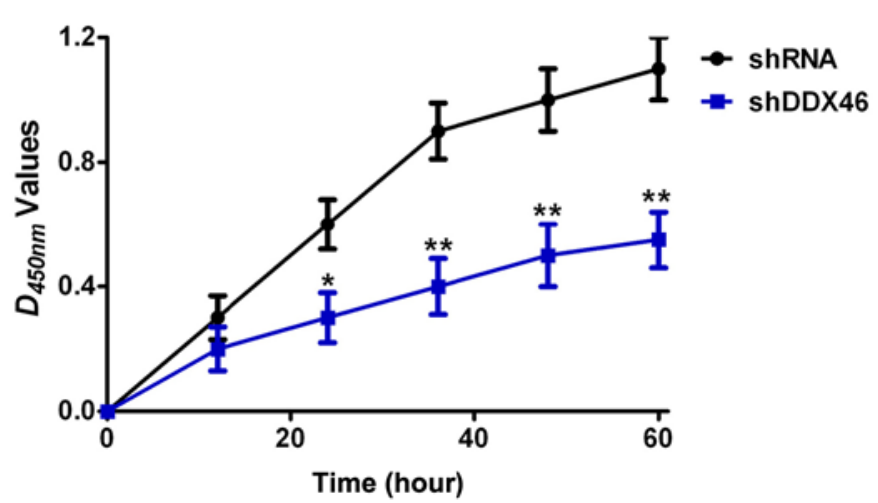

B

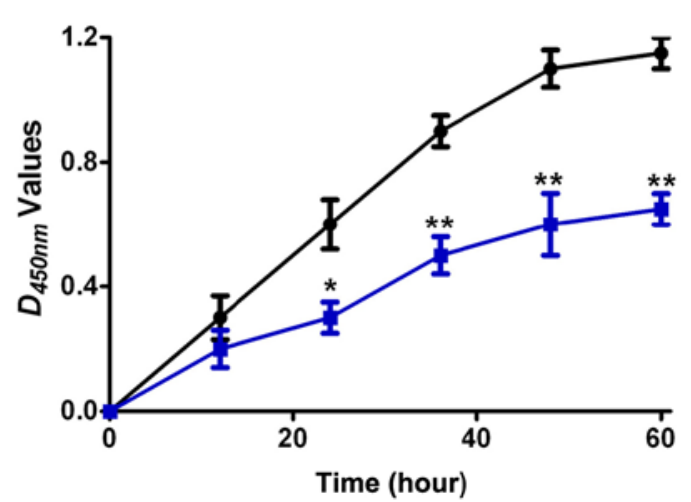

Figure 5. DDX46 silencing can inhibit cell proliferation. Cell Counting Kit- 8 assay results in (A) A431 and (B) SCL-1 cells. ${ }^{*}<0.05$ and ${ }^{* *} \mathrm{P}<0.01$ vs. shNC. shRNA, short hairpin RNA; DDX46, DEAD-Box Helicase 46; NC, negative control; D, absorbance.
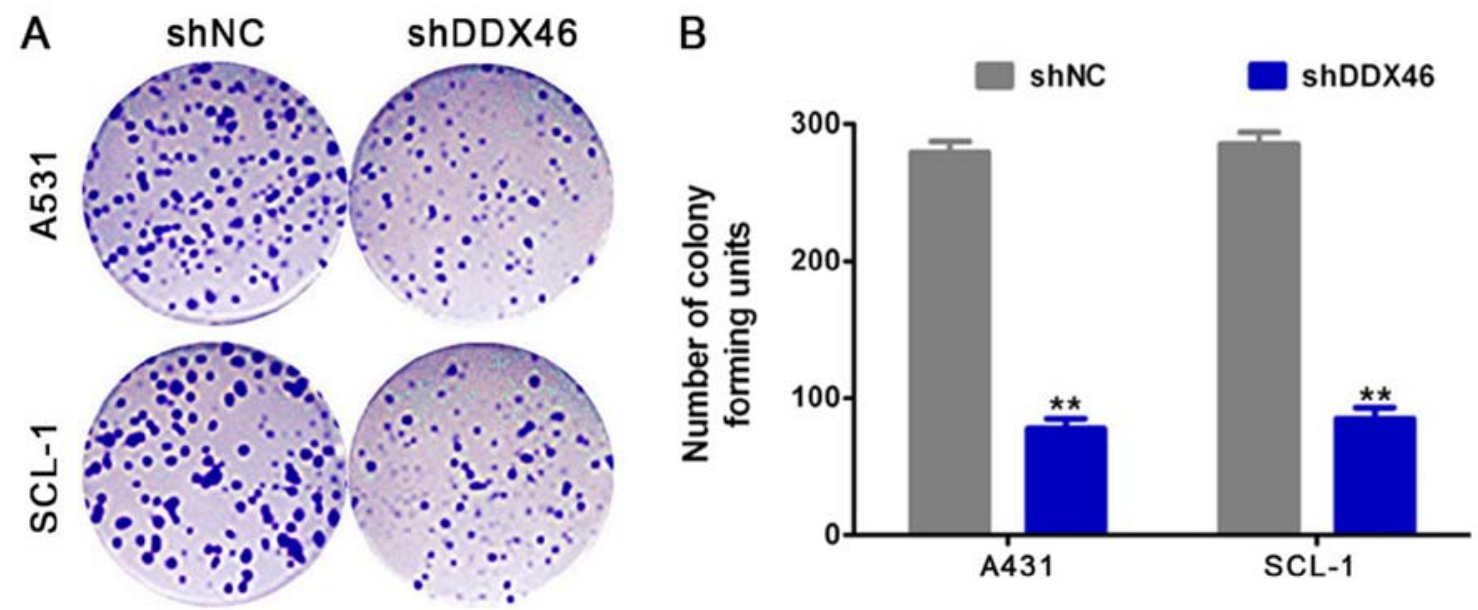

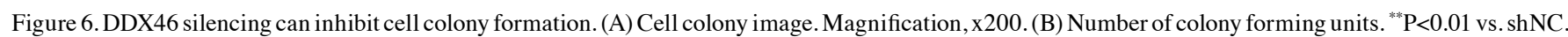
shRNA, short hairpin RNA; DDX46, DEAD-Box Helicase 46; NC, negative control.

DDX46 silencing inhibits cell apoptosis. Flow cytometry was used to assess cell apoptosis and Western blotting was used to measure the expression levels of the apoptotic-related proteins
Bcl-2, Survivin, Bax and cleaved caspase-3. It was demonstrated that the apoptotic rate was significantly increased in the shDDX46 group, compared with shNC group ( $\mathrm{P}<0.05$; Fig. 8). 

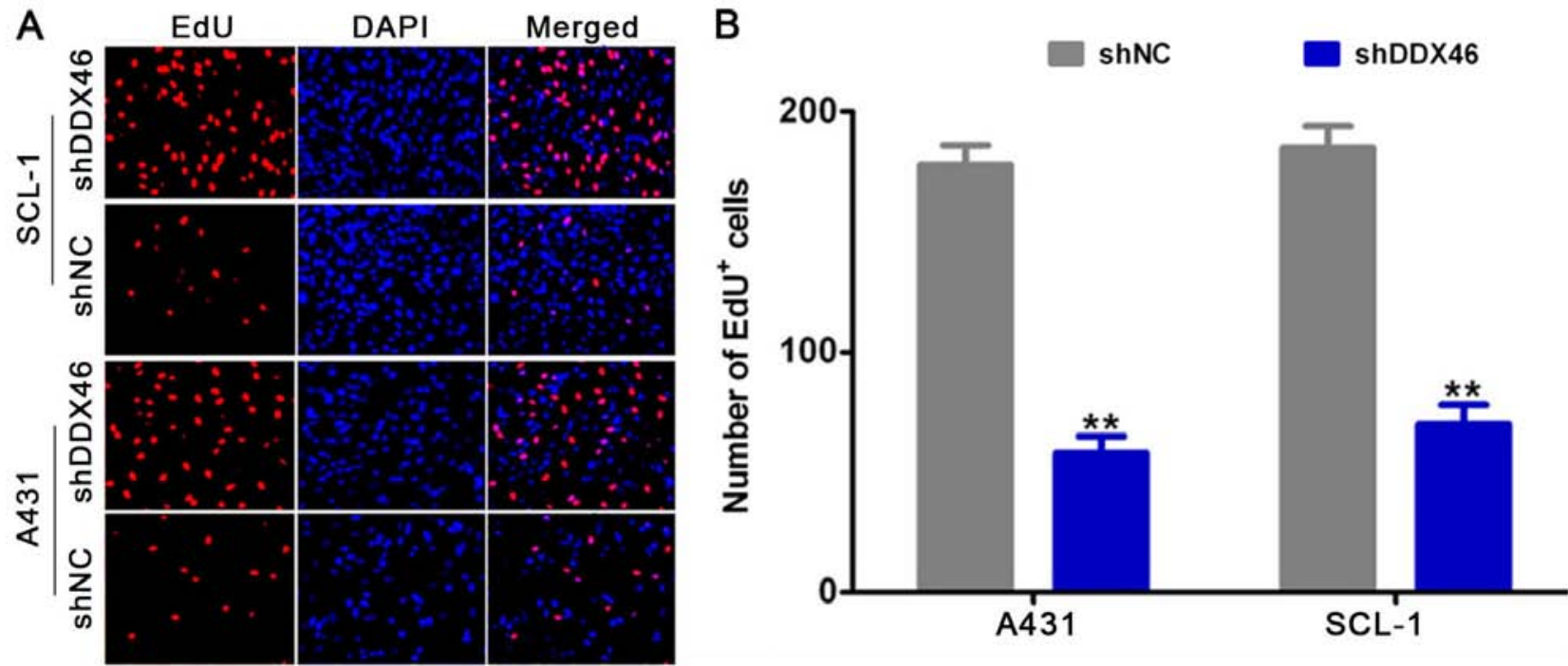

Figure 7. DDX46 silencing can inhibit DNA synthesis. (A) EdU staining image. Magnification, $x 200$. (B) Number of EdU ${ }^{+}$units. ${ }^{* *}$ P $<0.01$ vs. shNC. shRNA, short hairpin RNA; DDX46, DEAD-Box Helicase 46; NC, negative control; EdU, 5-ethynyl-2'-deoxyuridine.
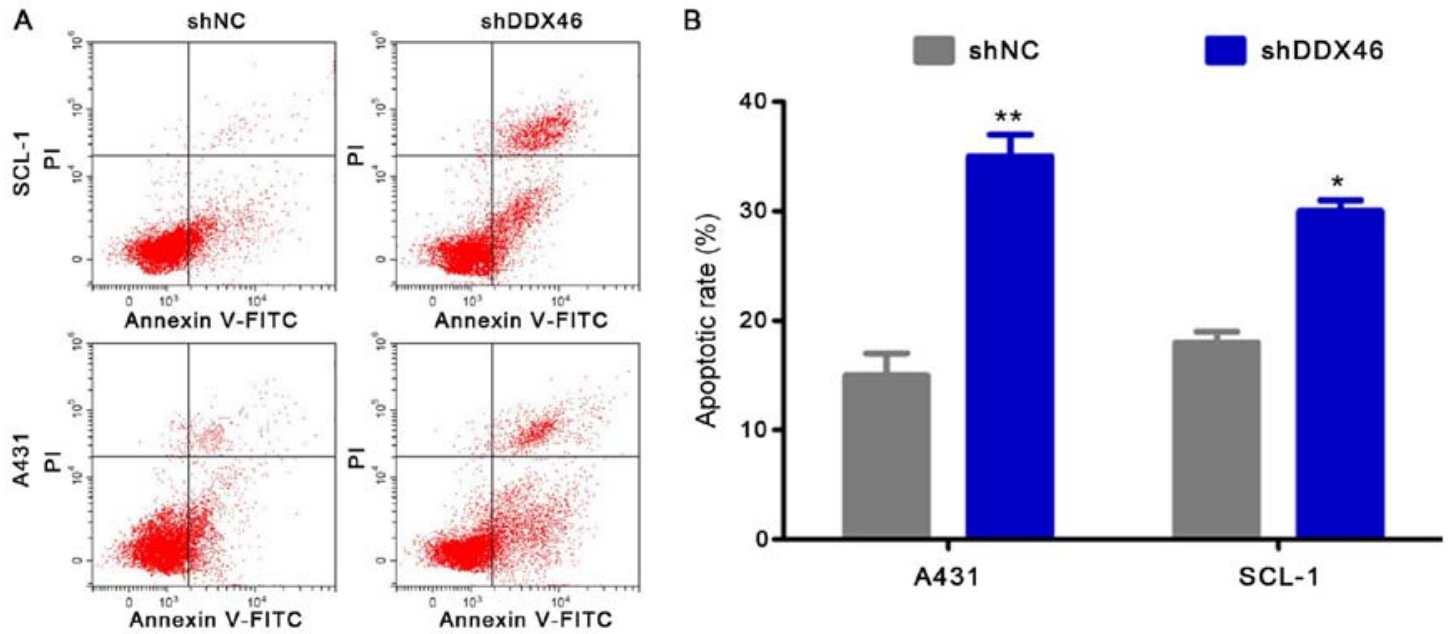

Figure 8. DDX46 silencing can promote cell apoptosis. (A) Annexin V- FITC/PI Image. Magnification, $\mathrm{x} 200$. (B) Apoptotic rate. ${ }^{*} \mathrm{P}<0.05$ and ${ }^{* *} \mathrm{P}<0.01$ vs. shNC. shRNA, short hairpin RNA; DDX46, DEAD-Box Helicase 46; NC, negative control; EdU, 5-ethynyl-2'-deoxyuridine.

Furthermore, Western blotting results indicated that the protein expression levels of Bcl-2 and Survivin were significantly decreased in the shDDX46 group, and that the protein expression levels of Bax and cleaved caspase-3 protein were significantly increased in shDDX46 group $(\mathrm{P}<0.05 ;$ Fig. 9).

DDX46 silencing can activate cell autophagy. Western blotting was used to detect the protein expression levels of Beclin1 and LC3 II/I. It was demonstrated that the protein expression levels of Beclin1 protein and the ratio of LC3 II/I were significantly increased in the shDDX46 group compared with the shNC group $(\mathrm{P}<0.05$; Fig. 10).

\section{Discussion}

RNA helicase is essential for RNA metabolism, including RNA splicing, transcription, transport, translation and degradation (7). DDX is an important ATP-dependent RNA helicase family, which exists in almost all prokaryotes and eukaryotes (11). Furthermore, DDX plays an important role in RNA metabolism, it is required for RNA functions, including gene transcription, RNA precursor mothering, ribosome synthesis, RNA output, translation initiation and RNA degradation $(12,13)$. Several DDX RNA helicase subtypes have been reported to be abnormally expressed in various cancer types (14). Previous studies have shown that DDX1 is overexpressed in retinoblastoma, transitional blastoma, breast cancer and testicular cancer $(15,16)$. Moreover, DDX5 is upregulated in human melanoma and hepatocellular carcinoma $(17,18)$, and DDX6 is increased in glioblastoma, rhabdomyosarcoma, lung cancer, colon cancer and liver cancer (19). Thus, the DDX family may be involved in the occurrence and progression cancer.

DDX46 is a member of the DDX RNA helicase family with ATP-dependent RNA helicase, that is located on chromosome 5q31.1 and plays a critical role in transcript splicing and ribosome assembly (20). Previous studies (21-23) in zebrafish have shown that DDX46 is required in the multilineage 
A
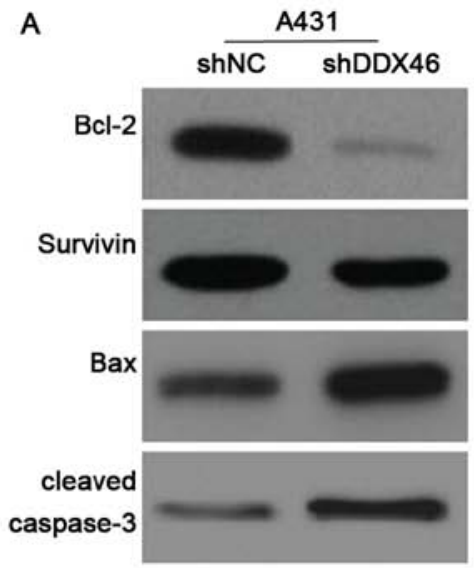

$\beta$-actin
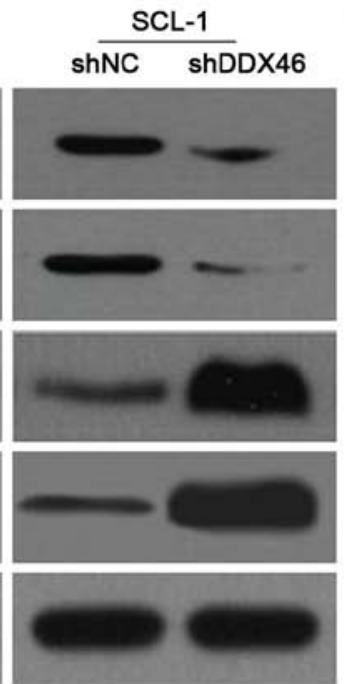

B

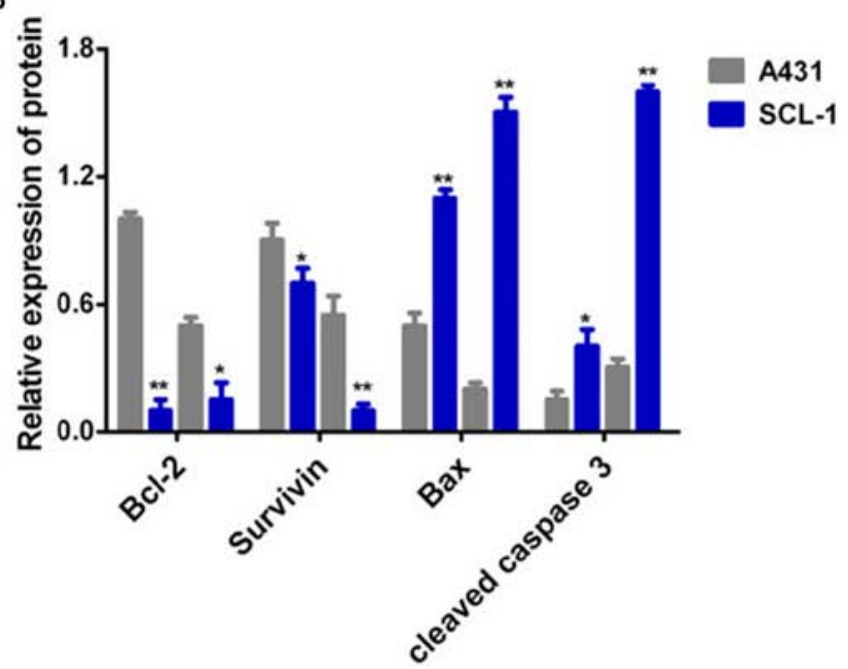

Figure 9. Protein expression levels of Bcl-2, Survivin, Bax and cleaved caspase-3 in A431 cells. (A) Western blotting results. (B) Relative protein expression level. "P<0.05 and ${ }^{* *} \mathrm{P}<0.01$ vs. shNC. shRNA, short hairpin RNA; DDX46, DEAD-Box Helicase 46; NC, negative control.

A

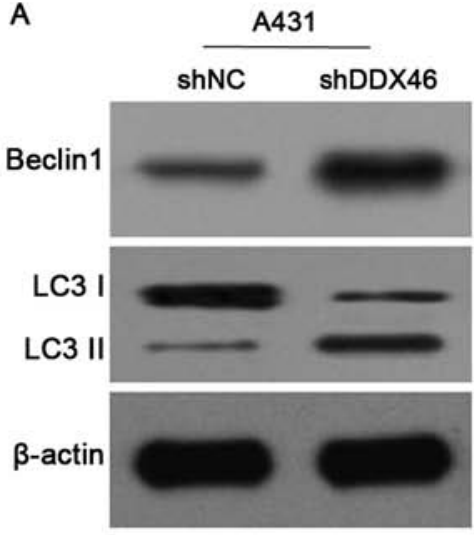

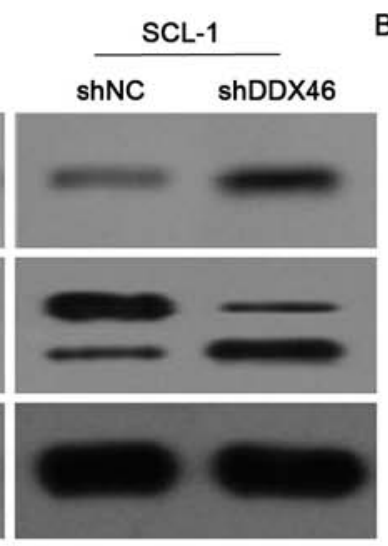

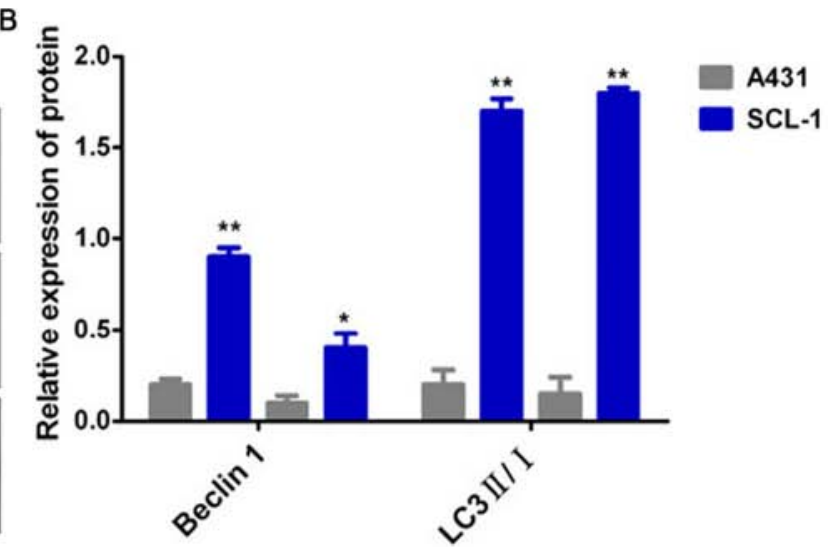

Figure 10. Protein expression levels of Beclin 1 and LC3 II/I. (A) Western blotting results. (B) Relative protein expression levels. "P<0.05 and ${ }^{* *} \mathrm{P}<0.01$ vs. shNC. shRNA, short hairpin RNA; DDX46, DEAD-Box Helicase 46; NC, negative control; LC3, microtubule-associated protein 1A/1B-light chain 3.

differentiation of hematopoietic stem cells and in the development of digestive organs and the brain. Li et al (24) reported that DDX46 is significantly overexpressed in colorectal cancer and that lentiviral DDX46 knockdown inhibits growth and induces apoptosis in human colorectal cancer cells. Liu et al (25) showed that DDX46 is upregulated in human bladder cancer 5637 and T24 cells. Li et al (26) found that DDX46 is significantly upregulated in esophageal squamous cell carcinoma tissues and cells, and that DDX46 knockdown decreases proliferation and increased apoptosis in TE-1 and Eca-109 cells. Thus, DDX46 may be involved in tumorigenesis and cancer progression. However, the role of DDX46 in CSCC still remains unknown.

The present results suggested that DDX46 was overexpressed in CSCC tissues, as indicated by results from IHC, RT-qPCR and Western blotting. The present study used DDX46 RNAi lentivirus to silence DDX46 expression in CSCC cells. It was found that DDX46 silencing can inhibit cell proliferation. Furthermore, DDX46 silencing can also induce cell apoptosis and activate autophagy by regulating the protein expression levels of Bcl-2, Survivin, Bax, cleaved caspase-3, Beclin1 and LC3 II/I. Thus, the present results suggested that DDX46 was overexpressed in CSCC and that DDX46 silencing can inhibit cell proliferation, the mechanism of which may be associated with apoptosis and autophagy. Previous studies have found that autophagy and apoptotic activity changes occur in a variety of human tumors $(26,27)$. In some cases, autophagy inhibits cell apoptosis, which promotes cell survival (28). In other instances, autophagy can induce cell death, or function alongside apoptosis to induce cell death in the case of apoptotic defect $(29,30)$. Thus, there is a close relationship between autophagy and apoptosis during cell death, and these pathways are interrelated and regulate each other. The present results indicated that apoptosis and autophagy worked together to inhibit CSCC cell proliferation.

In conclusion, to the best of our knowledge, the present study provides the first evidence that DDX46 was significantly overexpressed in CSCC. Furthermore, it was found that DDX46 silencing inhibited cell proliferation by inducing apoptosis and activating autophagy. Thus, DDX46 may serve as a novel potential therapeutic target for CSCC. 


\section{Acknowledgements}

Not applicable.

\section{Funding}

No funding was received.

\section{Availability of data and materials}

The datasets used and/or analyzed during the current study are available from the corresponding author on reasonable request.

\section{Authors' contributions}

LG and QL designed the study and performed the experiments. HJJ and DZ analyzed the data. All authors have read and approved the final manuscript.

\section{Ethics approval and consent to participate}

The present study was approved by the Ethics Committee of the First Hospital of Jilin University (Jilin, China), and written informed consent was obtained from all patients.

\section{Patient consent for publication}

Not applicable.

\section{Competing interests}

The authors declare that they have no competing interests.

\section{References}

1. Que SKT, Zwald FO and Schmults CD: Cutaneous squamous cell carcinoma: Incidence, risk factors, diagnosis, and staging. J Am Acad Dermatol 78: 237-247, 2018.

2. Ratushny V, Gober MD, Hick R, Ridky TW and Seykora JT: From keratinocyte to cancer: The pathogenesis and modeling of cutaneous squamous cell carcinoma. J Clin Invest 122: 464-472, 2012.

3. Umezono Y,Sato Y, Noto M, Yamada K, Noguchi N, Hasunuma N, Osada SI and Manabe M: Incidence rate of cutaneous squamous cell carcinoma is rapidly increasing in Akita Prefecture: Urgent alert for super-aged society. J Dermatol 46: 259-262, 2019.

4. Peters FS, Peeters AMA, Mandaviya PR, van Meurs JB, Hofland LJ, van de Wetering J, Betjes MG, Baan CC and Boer K: Differentially methylated regions in $\mathrm{T}$ cells identify kidney transplant patients at risk for de novo skin cancer. Clin Epigenetics 10: 81, 2018.

5. Jiang F, Zhang D, Li G and Wang X: Knockdown of DDX46 inhibits the invasion and tumorigenesis in osteosarcoma cells. Oncol Res 25: 417-425, 2017.

6. Nawaz G and Kang H: Rice OsRH58, a chloroplast DEAD-box RNA helicase, improves salt or drought stress tolerance in Arabidopsis by affecting chloroplast translation. BMC Plant Biol 19: 17, 2019.

7. Baek W, Lim CW and Lee SC: A DEAD-box RNA helicase, RH8, is critical for regulation of ABA signaling and the drought stress response via inhibition of PP2CA activity. Plant Cell Environ 41: 1593-1604, 2018.

8. Zheng Q, Hou J, Zhou Y, Li Z and Cao X: The RNA helicase DDX46 inhibits innate immunity by entrapping m6A-demethylated antiviral transcripts in the nucleus. Nat Immunol 18: 1094-1103, 2017.

9. Livak KJ and Schmittgen TD: Analysis of relative gene expression data using real-time quantitative PCR and the 2(-Delta Delta C(T)) Method. Methods 25: 402-408, 2001.
10. Schindelin J, Rueden CT, Hiner MC and Eliceiri KW: The Image J ecosystem: An open platform for biomedical image analysis. Mol Reprod Dev 82: 518-529, 2015.

11. Pauszek R, Lamichhane R, Rajkarnikar Singh A, van der Schans E and Millar D: The 5' nuclease domain of DNA polymerase I mediates a novel DNA transfer pathway during proofreading. Biophys J 114: 82a, 2018.

12. Sohn SO and Chay KO: The ATP-dependent RNA helicase, DDX42 interacts with paxillin and regulates apoptosis and polarization of Ba/F3 cells. Anim Cells Syst Seoul 23: 1-9, 2019.

13. Gao J, Byrd AK, Zybailov BL, Marecki JC, Guderyon MJ, Edwards AD, Chib S, West KL, Waldrip ZJ, Mackintosh SG, et al: DEAD-box RNA helicases Dbp2, Ded1 and Mss116 bind to G-quadruplex nucleic acids and destabilize G-quadruplex RNA. Chem Commun (Camb) 55: 4467-4470, 2019.

14. Curmi F and Cauchi RJ: The multiple lives of DEAD-box RNA helicase DP103/DDX20/Gemin3. Biochem Soc Trans 46: 329-341, 2018.

15. Tang J, Chen H, Wong CC, Liu D, Li T, Wang X, Ji J, Sung JJ, Fang JY and Yu J: DEAD-box helicase 27 promotes colorectal cancer growth and metastasis and predicts poor survival in CRC patients. Oncogene 37: 3006-3021, 2018.

16. Ribeiro de Almeida C, Dhir S, Dhir A, Moghaddam AE, Sattentau Q, Meinhart A and Proudfoot NJ: RNA helicase DDX1 converts RNA G-Quadruplex structures into R-Loops to promote IgH class switch recombination. Mol Cell 70: 650-662.e8, 2018.

17. Zhong W, Li Z, Zhou M, Xu T and Wang Y: DDX1 regulates alternative splicing and insulin secretion in pancreatic $\beta$ cells. Biochem Biophys Res Commun 500: 751-757, 2018.

18. Wu N, Jiang M, Han Y, Liu H, Chu Y, Liu H, Cao J, Hou Q, Zhao Y, Xu B, et al: O-GlcNAcylation promotes colorectal cancer progression by regulating protein stability and potential catcinogenic function of DDX5. J Cell Mol Med 23: 1354-1362, 2019.

19. Huang W, Thomas B, Flynn RA, Gavzy SJ, Wu L, Kim SV, Hall JA, Miraldi ER, Ng CP, Rigo F, et al: Retraction note: DDX5 and its associated lncRNA Rmrp modulate TH17 cell effector functions. Nature 562: 150, 2018.

20. Taniguchi K, Iwatsuki A, Sugito N, Shinohara H, Kuranaga Y, Oshikawa Y, Tajirika T, Futamura M, Yoshida K, Uchiyama K, et al: Oncogene RNA helicase DDX6 promotes the process of c-Myc expression in gastric cancer cells. Mol Carcinog 57: 579-589, 2018.

21. Lumb JH, Li Q, Popov LM, Ding S, Keith MT, Merrill BD, Greenberg HB, Li JB and Carette JE: DDX6 Represses Aberrant Activation of Interferon-Stimulated Genes. Cell Rep 20: 819-831, 2017.

22. Hirabayashi R, Hozumi S, Higashijima S and Kikuchi Y: Ddx46 is required for multi-lineage differentiation of hematopoietic stem cells in zebrafish. Stem Cells Dev 22: 2532-2542, 2013.

23. Hozumi S, Hirabayashi R, Yoshizawa A, Ogata M, Ishitani T, Tsutsumi M, Kuroiwa A, Itoh M and Kikuchi Y: DEAD-box protein Ddx46 is required for the development of the digestive organs and brain in zebrafish. PLoS One 7: e33675, 2012.

24. Li M, Ma Y, Huang P, Du A, Yang X, Zhang S, Xing C, Liu F and Cao J: Lentiviral DDX46 knockdown inhibits growth and induces apoptosis in human colorectal cancer cells. Gene 560: 237-244, 2015.

25. Liu X, Zhang C, Huang D, et al: Construction of DDX46 lentiviral vector and its expression identification in human bladder cancer cells. Anhui Medical Journal, 2018 (In Chinese).

26. Li B, Li YM,He WT, Chen H, Zhu HW, Liu T,Zhang JH, Song TN and Zhou YL: Knockdown of DDX46 inhibits proliferation and induces apoptosis in esophageal squamous cell carcinoma cells. Oncol Rep 36: 223-230, 2016.

27. Mane SD and Kamatham AN: Ascorbyl stearate stimulates cell death by oxidative stress-mediated apoptosis and autophagy in HeLa cervical cancer cell line in vitro. 3 Biotech 9: 115, 2019.

28. Chen Q, Kang J and Fu C: The independence of and associations among apoptosis, autophagy, and necrosis. Signal Transduct Target Ther 3: 18-23, 2018.

29. Song S, Tan J, Miao Y, Li M and Zhang Q: Crosstalk of autophagy and apoptosis: Involvement of the dual role of autophagy under ER stress. J Cell Physiol 232: 2977-2984, 2017.

30. Yan X, Zhou R and Ma Z: Autophagy-cell survival and death. Adv Exp Med Biol 1206: 667-696, 2019.

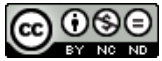

This work is licensed under a Creative Commons Attribution-NonCommercial-NoDerivatives 4.0 International (CC BY-NC-ND 4.0) License. 